\title{
Breastfeeding and Anesthesiologist
}

\author{
Jinlei Li, MD, PhD, MSc. \\ Department of Anesthesia, Yale New Haven Hospital, Yale University
}

Breastfeeding not only offers multiple advantages to infants, mothers and community [1], but also there was documented mortality when its initiation was delayed [2]. Infant health benefits range from decreased incidents of infectious disease or autoimmune disorders to lower risk of diabetes mellitus or obesity as well as likely neurodevelopmental outcome differences. Maternal benefits span from less postpartum bleeding and quicker return to pre-gestation weight (short term effects), to lowering breast malignancy and ovarian cancers (long term effects) [1]. On a community level using human milk has large-scale benefits on family, economics and environment, which have sustained the development of human milk banking. When it comes to contraindications of breastfeeding which are few to start with, American Academy of Pediatrics has detailed discussions on many problematic situations such as narcotics dependent mothers, street drug users, alcohol drinkers, smokers, and it also highly recommends LactMed (http://toxnet.nlm.nih.gov/newtoxnet/lactmed. $\mathrm{htm}$ ) for any residual uncertainties on various maternal medications [1].

Besides pediatrician and family doctors, anesthesiologists play an important role peri-operatively to maintain and facilitate breast-feeding. That is not to say there is great consistency in anesthesia practice on this matter. Nonetheless the diverse recommendations anesthesiologists provide to nursing-mothers are more due to obscurity of available research and clinical evidence than on account of well-founded controversy.

In this issue of Tranlational Perioperative and Pain Medicine, Dr. Cobb BT et al addressed the common questions many anesthesiologists encounter on a daily basis in this excellent article, "BREASTFEEDING AFTER ANESTHESIA: A Review for Anesthesia Providers Regarding the Transfer of Medications into Breast Milk"[3]. It not only reassured the safety on continuation and initiation of breastfeeding without delay under most clinical circumstances, it also offered anesthesiologists, among many other physicians, the opportunity to promote, protect and support breastfeeding in a safety manner.

Address for correspondence: Jinlei Li, MD, PhD, MSc. Department of Anesthesia, Yale New Haven Hospital, Yale University. Email: jinlei.li@yale.edu
Editor

Yuan-Xiang Tao, $\mathrm{PhD}, \mathrm{MD}$

Professor and Vice Chair of Research

Department of Anesthesiology

Rutgers, The State University of New Jersey

New Jersey Medical School

Disclosure of Funding

None

Additional publication details

Journal short name: Transl Perioper \& Pain Med

Received Date:June 15, 2015

Accepted Date: June 15, 2015

Published Date: June 15, 2015

Transl Perioper \& Pain Med 2015; 2(2):1

\section{Citation and Copyright}

Citation: Jinlei Li. Breastfeeding and anesthesiologist. Transl Perioper \& Pain Med 2015; 2(2): 1

Copyright: (C) 2015 Jinlei Li, MD. This is an open-access article distributed under the terms of the Creative Commons Attribution License, which permits unrestricted use, distribution, and reproduction in any medium, provided the original author and source are credited.

\section{References}

1. Breastfeeding and the use of human milk. Section on Breastfeeding. Pediatrics. 2012, 129(3):e827-41

2. Edmond KM, Zandoh C, Quigley MA, Amenga-Etego S, Owusu-Agyei S, Kirkwood BR. Delayed breastfeeding initiation increases risk of neonatal mortality. Pediatrics. 2006, 117(3):e380-6

3. Cobb BT, Liu R, Valentine EA, Onuoha OC. Breast feeding after anesthesia. A Review for anesthesia providers regarding the transfer of medications into breast milk. Transl Perioper \& Pain Med 2015; 2(2): $2-7$ 